\title{
Antimicrobial Synergic Effect of Chitosan with Sodium Lactate, Nisin or Potassium Sorbate against the Bacterial Flora of Fish
}

\author{
Laura Inés Schelegueda ${ }^{1,2}$, María Fernanda Gliemmo ${ }^{1} \&$ Carmen Adriana Campos ${ }^{1}$ \\ ${ }^{1}$ Departamento de Industrias, Facultad de Ciencias Exactas y Naturales, Universidad de Buenos Aires, Ciudad \\ Universitaria (1428), Ciudad Autónoma de Buenos Aires, Argentina \\ ${ }^{2}$ Consejo Nacional de Investigaciones Científicas y Técnicas de la República, Argentina \\ Correspondence: Carmen Adriana Campos, Departamento de Industrias, Facultad de Ciencias Exactas y \\ Naturales, Universidad de Buenos Aires, Ciudad Universitaria (1428), Ciudad Autónoma de Buenos Aires, \\ Argentina. Tel: 54-114-576-3366. E-mail: carmen@di.fcen.uba.ar
}

Received: June 6, 2012 Accepted: July 4, 2012 Online Published: July 27, 2012

doi:10.5539/jfr.v1n3p272 URL: http://dx.doi.org/10.5539/jfr.v1n3p272

\begin{abstract}
The inhibitory action of sodium lactate (SL), potassium sorbate (PS), nisin and chitosan against representative bacteria of fish spoilage flora (two Pseudomonas strains, Shewanella putrefaciens and Lactobacillus plantarum) and also against Listeria innосиа was assessed. Minimum inhibitory and bactericidal concentrations were determined. Antimicrobial interactions seeking for synergistic effects between binary mixtures were evaluated by isobolograms and by the fractional inhibitory concentrations (FIC). To study antimicrobials effects on a food matrix, selected mixtures showing synergistic action were tested in fish homogenates. Most antimicrobials inhibited bacterial growth. Isobolograms and FIC index showed that the combination of antimicrobials with chitosan and the mixture PS-SL exerted a synergistic action. Among them, combinations containing PS were discarded, since the levels needed may have adverse effects on the sensory characteristics of fish. Regarding to fish homogenates, chitosan in combination with SL, achieved the greater reduction of bacterial population, being useful for the preservation of minimally processed fish.
\end{abstract}

Keywords: sodium lactate, potassium sorbate, nisin, chitosan, fish bacterial flora

\section{Introduction}

Nowadays, consumers have become more demanding about the quality of the food. An increasing trend to consume natural food, with the least possible amount of chemical additives is found. Several compounds in nature are able to inhibit microorganisms growth (Roller, 2003). They can be derived from plants, animals or microorganisms. However, many of them have a limited spectrum of activity and are effective only at very high concentrations. Combining antimicrobial agents is a way to overcome these problems since a synergistic action may be observed allowing the use of lower concentrations and at the same time a wider spectra of microbial inhibition can be found. Regarding this topic, Ye, Neetoo and Chen (2008a; 2008b) reported that chitosan coated film containing sodium lactate or potassium sorbate produced a higher inhibition of Listeria monocytogenes than chitosan films alone on cold smoked salmon or ham steaks, respectively.

Fishery products are highly perishable food due to their composition. The process of degradation involves chemical and enzymatic reactions, but it is dominated mainly by the growth of microorganisms (Olafsdóttir et al., 1997). Therefore, the use of a preservation method is essential to extend their shelf life. In the context of the hurdle technology, the use of antimicrobials together with other preservation factors has proved to be a good option (Roller, 2003). The knowledge of the effect of different antimicrobials on the inhibition of microflora would optimize their use.

Natural antimicrobials are proposed to be used in many fishery products. Sodium lactate (SL) is known to have antibacterial effects against many spoilage and pathogenic microorganisms (Stekelenburg \& Kant-Muermans, 2001; Long \& Phillips, 2003; Sallam, 2007). It was originally added to food in order to act as humectant and flavor enhancer. However, nowadays SL is also used to extend the shelf life of many products, including fish (Long \& Phillips, 2003; Juneja, 2006; Sallam, 2007). It is non-toxic and commonly available (Stekelenburg \& Kant-Muermans, 2001; Aran, 2001; Long \& Phillips, 2003; Sallam, 2007). Moreover, it induces less adverse effect on sensory characteristics than lactic acid does (Nykänen, Weckman, \& Lapveteläinen, 2000). Potassium sorbate (PS) is widely used as preservative in many foods because of its effectiveness against yeasts, molds and 
many bacteria. Its inhibitory action depends on the type of food, the processing and storage conditions and the concentration used (Sofos, 2000). Nisin is an antibacterial polypeptide produced by Lactococcus lactis. It belongs to the group of inhibitors called bacteriocins (Thomas \& Delves Broughton Hoover, 2005) and it effectively inhibits Gram-positive bacteria and also the outgrowth of spores of Bacilli and Clostridia (Gandhi \& Chikindas, 2007). Chitosan is a natural biopolymer derived from deacetylation of chitin, a major component of the shells of crustacean (No, Meyers, Prinyawiwatkul, \& Xu, 2007). It is non-toxic and it has anti-oxidative activity and biodegradability (Fan et al., 2009). Antibacterial activity of chitosan depends on deacetylation degree, molecular weight, temperature, $\mathrm{pH}$ of the medium and other components presence (Devlieghere, Vermeulen, \& Debevere, 2004).

As previously mentioned, growth of microorganisms promotes the spoilage of fish products. Preservation method applied and storage conditions determine the kind of flora. Lactic acid bacteria, such as Lactobacillus spp., are selected by the use of $\mathrm{CO}_{2}$ atmosphere in the packaging or by the addition of low levels of $\mathrm{NaCl}$. Gram-negative fermentative and pychrotolerant bacteria (Pseudomonas spp. and Shewanella spp.) growth is observed on unpreserved chilled fish (Gram \& Dalgaard, 2002). Furthermore, none of the methods typically used to preserve seafood can control the presence of L. monocytogenes, which is able to grow at low $\mathrm{pH}$ values, refrigeration temperatures and high salt concentrations (Gandhi \& Chikindas, 2007). For this reason, the pathogen is usually isolated from seafood and the searching of new methods to control its growth is necessary. Based on the topics discussed, the aim of this study is to explore the effectiveness of different antimicrobials to find synergistic combinations to inhibit the growth of spoilage bacteria typically found in fish products and also to control the growth of Listeria.

\section{Materials and Methods}

\subsection{Bacterial Strains}

Four spoilage bacteria usually isolated from seafood were used in this study: Pseudomonas aeruginosa ATCC 9027, Pseudomonas fluorescens ATCC 49838, Shewanella putrefaciens ATCC 8071, and Lactobacillus plantarum ATCC 8014. Listeria innocua 6a ATCC 33090 was used to emulate Listeria monocytogenes because of its similar response to stress factors (Friedly et al., 2008). All of them were purchased from Medicatec S.A. (Argentina).

All strains were stored at $-30^{\circ} \mathrm{C}$ in Mueller Hinton broth (Biokar Diagnostics, Beauvais, France) plus $10 \%(\mathrm{w} / \mathrm{w})$ glycerol (Sintorgan S. A., Buenos Aires, Argentina) and 10\% (w/w) skim milk. Before the use, they were grown twice in Mueller Hinton broth at $30 \pm 1^{\circ} \mathrm{C}$ during 18 hours.

\subsection{Antimicrobial Agents}

Sodium lactate (SL) (Parafarm, Buenos Aires, Argentina) and potassium sorbate (PS) (Sigma, Germany) were dissolved in Mueller Hinton broth and $\mathrm{pH}$ was adjusted to 5.5 using a drop of $10 \%(\mathrm{w} / \mathrm{w})$ citric acid (Parafarm, Buenos Aires, Argentina). Nisin was added in the form of Nisaplin (Danisco A/S DK, Denmark), it contains $10^{6}$ $\mathrm{IU} \mathrm{g}^{-1}$. Nisaplin was dissolved in distilled water acidified to $\mathrm{pH} 2.0$ with $\mathrm{HCl}$ plus $0.75 \%(\mathrm{w} / \mathrm{w}) \mathrm{NaCl}$, under these conditions it may be autoclaved without loss of activity (Thomas \& Delves Broughton Hoover, 2005). Chitosan, (Sigma, U.S.A.) with a deacetylated degree of $85 \%$, was dispersed in $1.0 \%(w / w)$ acetic acid solution under gentle stirring (Anedra S.A., Buenos Aires, Argentina) and $\mathrm{pH}$ was adjusted to 5.5 using $0.4 \mathrm{M} \mathrm{NaOH}$. All solutions were autoclaved at $121^{\circ} \mathrm{C}$ for 15 minutes. Before using the solution of Nisaplin, $\mathrm{pH}$ was adjusted to 5.5 using sterilized $0.4 \mathrm{M} \mathrm{NaOH}$.

To evaluate the possible contribution of water activity $\left(a_{w}\right)$ depression to bacterial growth inhibition, $a_{w}$ of antimicrobial solutions was measured with an Aqualab dewpoint electronic humidity meter (Decagon Devices Inc., Pullman, Wash., U.S.A.). The experimental error in $\mathrm{a}_{\mathrm{w}}$ determination is $\pm 0.005 \mathrm{a}_{\mathrm{w}}$ units when using humidity meter according to Roa and Tapia (1991).

\subsection{Determination of Minimum Inhibitory and Minimum Bactericidal Concentrations}

The minimum inhibitory concentration (MIC) was determined by a microdilution method in 96 well-round bottomed sterilized microtitre plates (Kartell S.p.a., Italy). Serial dilutions of each antimicrobial were prepared in Mueller Hinton broth at $\mathrm{pH}$ 5.5. Mueller Hinton is recommended as the medium for susceptibility testing of aerobic and facultative anaerobic bacteria (National Committee for Clinical Laboratory Standards [NCCLS], 1999). Portions of $90 \mu \mathrm{L}$ of the diluted antimicrobials were pipetted into the wells of the microtitre plates, together with $10 \mu \mathrm{L}$ of a $10^{6} \mathrm{CFU} \mathrm{mL}^{-1}$ culture of each microorganism, once a time. The range of concentrations tested were from 7.0 to $2000 \mathrm{ppm}$ for chitosan, from 16.0 to $4300 \mathrm{IU} \mathrm{g}^{-1}$ for nisin, from 35.0 to $9000 \mathrm{ppm}$ for PS and from 281 to $18000 \mathrm{ppm}$ for SL. Microtitre plates were incubated at $30 \pm 1^{\circ} \mathrm{C}$ for 24 hours. The visual detection of turbidity in the wells, as compared with the negative and positive controls, was considered as the 
absence of inhibition. Negative and positive controls were tested in parallel, being the former no inoculated Mueller Hinton broth, and the latter inculated Mueller Hinton broth free of antimicrobials. The MIC was defined as the highest dilution showing inhibition after 24 hours of incubation according to the NCCLS (1999) recommendations.

All the experiments were made in duplicate and replicated at least twice.

To rule out the effect of acetic acid (used to dissolve chitosan) on the development of the studied microorganisms, a similar trial was conducted. For this purpose, serial dilutions of acetic acid, from 1.00 to $0.25 \%(\mathrm{w} / \mathrm{w})$ were prepared in Mueller Hinton broth, and $\mathrm{pH}$ was adjusted to 5.5 using sterilized $0.4 \mathrm{M} \mathrm{NaOH}$.

To determine minimum bactericidal concentrations (MBC), $35 \mu \mathrm{L}$ aliquots from wells where growth was inhibited were spread on Mueller Hinton agar plates and then they were incubated at $30 \pm 1^{\circ} \mathrm{C}$ for 48 hours. The $\mathrm{MBC}$ was defined as the lowest antimicrobial concentrations of the plate where no growth was detected (Owen $\&$ Palombo, 2007).

\subsection{Evaluation of Antimicrobial Interactions}

Serial dilutions of two antimicrobials were mixed in a microtitre plate so that each row or column contained a fixed amount of the first antimicrobial and increasing amounts of the second one. Each plate also contained a row and a column in which each antimicrobial was present alone (Singh et al., 2000). The microtitre plates were inoculated with $10 \mu \mathrm{L}$ of a $10^{6} \mathrm{CFU} \mathrm{mL}^{-1}$ culture of each microorganism. All antimicrobials were combined with each other, so that six combinations were obtained.

The MIC of each antimicrobial, alone and in combination with the others was used to graph the isobolograms. Fractional inhibitory concentrations (FIC) were also calculated. They are defined as the relationship of the MIC of an antimicrobial when combined $\left(\mathrm{MIC}_{\mathrm{A}-\mathrm{B}}\right.$ or $\left.\mathrm{MIC}_{\mathrm{B}-\mathrm{A}}\right)$ divided by the $\mathrm{MIC}$ of this antimicrobial when used alone $\left(\mathrm{MIC}_{\mathrm{A}}\right.$ or $\left.\mathrm{MIC}_{\mathrm{B}}\right)$. Fractional inhibitory concentrations of each pair of antimicrobials were added to obtain the FIC index: $\mathrm{FIC}_{\mathrm{I}}=\left(\mathrm{MIC}_{\mathrm{A}-\mathrm{B}} / \mathrm{MIC}_{\mathrm{A}}\right)+\left(\mathrm{MIC}_{\mathrm{B}-\mathrm{A}} / \mathrm{MIC}_{\mathrm{B}}\right)$. Considering the $\mathrm{FIC}$ index value, the type of interaction between the antimicrobials can be determined. A FIC index value near to 1 indicates an additive effect; if less than 1 it indicates synergism; and if greater than 1, the interaction is antagonic (Lopez Malo Vigil, Palou, Parish, \& Davidson, 2005). A possible synergistic action was proposed when an antimicrobial alone was not able to inhibit the growth of the target bacteria. But when it is used in combination with another antimicrobial, the amount of the former was smaller than the maximum amount assayed alone and the amount of the second was smaller than the one needed when it is used alone.

\subsection{Evaluation of Antimicrobial Mixtures on Fish Homogenates}

Since chitosan-SL and chitosan-nisin combinations were the most effective as antimicrobial mixtures, they were selected to test their ability to inhibit the growth of the target bacteria in fish homogenates. For that purpose, 5 sets of samples were carried out: homogenates without antimicrobials (C), homogenates with $40 \mathrm{ppm}$ of chitosan and $13500 \mathrm{ppm}$ of SL $\left(\mathrm{Ch}_{1}-\mathrm{SL}_{1}\right)$, homogenates with $400 \mathrm{ppm}$ of chitosan and $27000 \mathrm{ppm}$ of SL $\left(\mathrm{Ch}_{2}-\mathrm{SL}_{2}\right)$, homogenates with $60 \mathrm{ppm}$ of chitosan and $600 \mathrm{IU} \mathrm{g}^{-1}$ of nisin $\left(\mathrm{Ch}_{3}-\mathrm{N}_{1}\right)$ and homogenates with $300 \mathrm{ppm}$ of chitosan and $3000 \mathrm{IU} \mathrm{g}^{-1}$ of nisin $\left(\mathrm{Ch}_{4}-\mathrm{N}_{2}\right)$. These antimicrobials concentrations were selected considering globally all FIC values, the information available about sensorial acceptability and the fact that effectiveness of antimicrobials can be reduced in food matrixes (Roller, 2003).

Fish homogenates were prepared processing Argentine hake fillets (Merluccius hubbsi) and distilled water in a ratio of $1: 1 ; \mathrm{pH}$ was adjusted to 5.5 using citric acid $10 \%(\mathrm{w} / \mathrm{w})$. Aliquots were put into screw-cap flasks and sterilized for 15 minutes at $100^{\circ} \mathrm{C}$. Antimicrobials combinations were added to the fish homogenates in order to achieve the selected concentrations. Then microorganisms were inoculated reaching a level of $10^{5} \mathrm{CFU} \mathrm{g}{ }^{-1}$.

The inoculated homogenates were stored at $30 \pm 1{ }^{\circ} \mathrm{C}$ for 72 hours; samples were withdrawn at 0,24 and 72 hours. Microorganisms populations were enumerated by pour-plating in Mueller-Hinton agar and plates were incubated for 48 hours at $30 \pm 1^{\circ} \mathrm{C}$.

\subsection{Statistical Analysis}

Log of colony forming units per gram of sample of each microorganism were processed using the statistical program InfoStat 2011e (Argentina). A two-way repeated measures ANOVA followed by Tukey's multiple comparison test were performed to compare data obtained. The significance level was $0.05 \%$.

\section{Results and Discussion}

\subsection{Antimicrobial MICs and MBCs}

The effectiveness of antimicrobials for the inhibition of spoilage flora and L. innocua was assessed in this study. 
Experiments were done at $\mathrm{pH} 5.5$ since the action of the antimicrobials assayed is enhanced by decreasing the pH (Dykes, Hancock, \& Hastings, 1998; Sofos, 2000).

In general, antimicrobials tested were able to inhibit the growth of the microorganisms and MIC values depended on compound tested and bacteria target (Table 1). Mueller Hinton broth adjusted to $\mathrm{pH} 5.5$ presented an $\mathrm{a}_{\mathrm{w}}$ of 0.995 which was not modified by the addition of nisin, PS or chitosan. Conversely, the inclusion of $18000 \mathrm{ppm}$ of SL promoted a decrease in $\mathrm{a}_{\mathrm{w}}$ to 0.989 .

Acetic acid at the level used to dissolve chitosan did not influence the development of microorganisms demonstrating that the inhibition of the growth observed in the presence of chitosan can be attributed to its addition. Similar results were achieved by Tin, Sakharkar, Lim, \& Sakharkar (2009) when the effect of acetate buffer was evaluated in contrast to the activity of chitosan.

Table 1. Minimum inhibitory concentrations (MIC) and minimum bactericidal concentrations (MBC) obtained

\begin{tabular}{|c|c|c|c|c|c|c|c|c|}
\hline \multirow[t]{2}{*}{ Microorganism } & \multicolumn{4}{|l|}{ MIC } & \multicolumn{4}{|l|}{ MBC } \\
\hline & $\begin{array}{l}\text { Chitosan } \\
\text { (ppm) }\end{array}$ & $\begin{array}{l}\text { Nisin } \\
\left(\mathrm{IU} \mathrm{g}^{-1}\right)\end{array}$ & $\begin{array}{l}\text { PS } \\
(\mathrm{ppm})\end{array}$ & $\begin{array}{l}\text { SL } \\
\text { (ppm) }\end{array}$ & $\begin{array}{l}\text { Chitosan } \\
\text { (ppm) }\end{array}$ & $\begin{array}{l}\text { Nisin } \\
\left(\mathrm{IU} \mathrm{g}^{-1}\right)\end{array}$ & $\begin{array}{l}\text { PS } \\
(\mathrm{ppm})\end{array}$ & $\begin{array}{l}\mathrm{SL} \\
(\mathrm{ppm})\end{array}$ \\
\hline P. aeruginosa & 62 & $>4300$ & 4500 & 13500 & $>2000$ & $>4300$ & $>9000$ & $>18000$ \\
\hline P. fluorescens & 108 & $>4300$ & 4500 & 13500 & $>2000$ & $>4300$ & $>9000$ & $>18000$ \\
\hline S. putrefaciens & 125 & 1075 & 4500 & $>18000$ & $>2000$ & $>4300$ & $>9000$ & $>18000$ \\
\hline L. plantarum & 27 & 1183 & 9000 & $>18000$ & $>2000$ & $>4300$ & $>9000$ & $>18000$ \\
\hline L. innocua & 96 & 1183 & 4500 & 18000 & $>2000$ & $>4300$ & $>9000$ & $>18000$ \\
\hline
\end{tabular}

The smallest MIC values corresponded to chitosan suggesting that this compound is very effective to control the growth of all bacteria tested, being L. plantarum the most sensitive of the studied bacteria (Table 1). The range of chitosan MIC obtained was in accordance with the MIC values previously reported (Devlieghere et al., 2004; Tin et al., 2009).

As expected, nisin inhibited the growth of L. innocua and L. plantarum being the MIC equal for both bacteria. It is well known the ability of nisin for inhibiting Gram positive bacteria, especially Listeria (Adams, 2003). Nisin was not able to inhibit the growth of Pseudomonas or it is necessary to add a higher level than the one used. The lack of effectiveness of this agent is linked with the fact that Gram negative bacteria are resistant to nisin because of their impermeable outer cell membrane, which prevents nisin reaching the cytoplasmic membrane (Thomas, Clarkson, \& Delves-Broughton, 2000). However, nisin was able to inhibit the growth of S. putrefaciens. Probably, the adjustment of $\mathrm{pH}$ to 5.5 damaged the outer membrane and nisin could access to the cytoplasm and cause inhibition. Previous studies have reported that $S$. putrefaciens growth rate decreases at acidic $\mathrm{pH}$ (Boskou \& Debevere, 1998).

Potassium sorbate inhibited the growth of all bacteria assayed and the MIC value against $L$. plantarum was 9000 ppm being two fold higher than those obtained for the rest of bacteria assayed. Sensitivity of PS towards lactic acid bacteria shows great differences depending on strain tested. Many of them are resistant to sorbic acid even this antimicrobial is used as a selective agent in cucumber fermentations since it inhibits yeast growth while it allows the lactic acid bacteria development (Sofos, 2000).

Sodium lactate inhibited the growth of Pseudomonas and L. innocua. This trend is in agreement with that reported by Sallam et al. (2007). Lactates inhibit microbial growth by depressing $\mathrm{a}_{\mathrm{w}}$ and by the action of their undissociated form (Abou-Zeid et al., 2007). Probably, in the studied systems a combination of both mechanisms would be present. Moreover, the ability of lactates to inhibit or delay the growth of Listeriae has been extensively reported (Buncic, Fitzgerald, Bell \& Hudson, 1995; Abou-Zeid et al., 2007). The addition of 18000 ppm of the antimicrobial failed to inhibit $S$. putrefaciens and $L$. plantarum growth. There is previous evidence showing that lactates were able to inhibit the growth of Salmonella and $L$. sake but allowed the growth of $L$. plantarum (Yeh, Hoogetoorn, \& Chen, 2004).

Addition of PS proved to be more effective than SL, since the MICs of the second were higher. However, PS MIC values seem to be very high from the sensory point of view, while LS concentrations within the range of 10 000 to $30000 \mathrm{ppm}$ are acceptable in meat (Buncic et al., 1995).

In summary, L. innocua growth was inhibited by the four antimicrobials tested. Both Pseudomonas were inhibited by all studied preservatives except by nisin. Finally, S. putrefaciens and L. plantarum growth were 
inhibited by all of them except by SL. Despite this, no bactericidal effect was shown (Table 1). The highest concentrations of the antimicrobials tested were not enough to inactivate the microorganisms, which were able to grow in an environment free of additives. This trend confirmed that antimicrobials can not be used as a single stress factor and must be used as one stress factor in a multi-hurdle preservation process.

\subsection{Antimicrobial Interactions}

The combined use of chitosan and PS exerted a synergistic action on Pseudomonas, S. putrefaciens and $L$. innocua growth (Table 2). At $\mathrm{pH}$ 5.5, chitosan is a polycationic compound and can interact with the anionic components of the microbial surface (No et al., 2007), which may facilitate the energy-dissipating action of PS explaining the synergism observed. Regarding the action on $L$. plantarum, an additive effect was observed. From previous studies, the information about the joint used of chitosan and PS was focused on the use of chitosan as a film-forming agent and in some cases an antagonism against Lactobacillus spp., E. coli and S. typhimurium was reported due to the interaction between the amino groups of chitosan and the carboxylic group of sorbates (Fan et al., 2009; Vasconez, Flores, Campos, Alvarado \& Gerschenson, 2009).

When chitosan was combined with SL, a synergistic effect on Pseudomonas and L. innocua inhibition was observed (Table 2). Moreover, inclusion of $18000 \mathrm{ppm}$ of SL alone did not inhibit the growth of L. plantarum or S. putrefaciens (Table 1), but the joint presence of $13500 \mathrm{ppm}$ of SL together with $16 \mathrm{ppm}$ of chitosan or 6750 ppm of SL together with $27 \mathrm{ppm}$ of chitosan produced the inhibition of L. plantarum or S. putrefaciens, respectively. Mentioned trends suggest the existence of a possible synergistic interaction (Table 2). Probably, this action was related to the electrostatic interactions as it was mentioned previously.

Incorporation of nisin to chitosan systems produced different trends depending on target microorganism (Table 2). A synergistic action was observed on $S$. putrefaciens and an additive action on L. innocua. Finally, no interaction was detected on Pseudomonas and L. plantarum. Regarding the effect on S. putrefaciens, chitosan acted as a membrane-permeabilising agent through the disruption of the outer membrane cooperating with the action of nisin. Cai et al. (2010) established by Fourier Transform Infrared Spectroscopy that chitosan and nisin formed complexes through electrostatic interactions between the protonated amino group of chitosan and the carboxilate ion of nisin. This complex had higher antimicrobial activity against several Gram-negative bacteria than each antimicrobial alone.

The joint use of nisin and SL did not modify the pattern of inhibition of each preservative alone on target bacteria (Table 2). Regarding Pseudomonas, the addition of nisin did not change the MIC of SL. In the case of $S$. putrefaciens, the addition of SL did not change the MIC of nisin. Finally, both antimicrobials inhibited $L$. innocua being necessary the MIC of each one since they did not interact. However, a synergistic action of nisin and lactate was reported in cold smoked rainbow trout (Nykänen et al., 2000). In addition to this, Neetoo, Ye and Chen (2008) found that the incorporation of sodium lactate and nisin to salmon pate produced a higher inhibition of $L$. monocytogenes compared to that of nisin alone.

The combined use of nisin and PS did not reveal any interaction between both antimicrobials (Table 2). For Pseudomonas, PS inhibited the growth and nisin did not modify the trend. For the rest of bacteria, it was necessary a concentration equal to the MIC of each antimicrobial alone to inhibit the growth since they did not interact. It must be mentioned that in other studies, the combination of PS and nisin had the best preservative effect when compared to the results for each preservative used alone. Buncic et al. (1995) and Fang, C. Chen and H. Chen. (1997) reported that the combined use of mentioned preservatives extended the shelf-life of vegetarian foods by inhibiting growth of L. monocytogenes, S. aureus $\mathrm{C} 10$ and B. cereus B7. However, according to Hurst $\&$ Hoover (1993), addition of sorbic acid counteracted the antimicrobial activity of nisin.

Table 2. Interactions between studied antimicrobials

\begin{tabular}{lcccccc}
\hline \multirow{2}{*}{ Microorganism } & \multicolumn{5}{c}{ Antimicrobial combinations } \\
\cline { 2 - 7 } P. aeruginosa & Chitosan-PS & Chitosan-SL & Chitosan-Nisin & Nisin-SL & Nisin_PS & PS-SL \\
\cline { 2 - 7 } P. fluorescens & $\mathrm{S}(0.68)$ & $\mathrm{S}(0.61)$ & $\mathrm{NI}$ & $\mathrm{NI}$ & $\mathrm{NI}$ & $\mathrm{S}(0.75-0.92)$ \\
S. putrefaciens & $\mathrm{S}(0.75)$ & $\mathrm{S}(0.39-0.82)$ & $\mathrm{NI}$ & $\mathrm{NI}$ & $\mathrm{NI}$ & $\mathrm{S}-\mathrm{A}(0.56-1.01)$ \\
L. plantarum & $\mathrm{S}(0.48)$ & $\mathrm{S}^{(1)}$ & $\mathrm{S}(0.47)$ & $\mathrm{NI}$ & $\mathrm{NI}$ & $\mathrm{S}^{(1)}$ \\
L. innocua & $\mathrm{A}(0.99)$ & $\mathrm{S}^{(1)}$ & $\mathrm{NI}$ & $\mathrm{NI}$ & $\mathrm{NI}$ & $\mathrm{NI}$ \\
\hline
\end{tabular}

NI: no interaction; S: synergistic interaction; $\mathrm{S}^{(1)}$ Possible synergistic interaction; A: additive interaction. Number between brackets are FIC indexes. 
The joint use of PS and SL exerted a synergistic effect on the inhibition of Pseudomonas and L. innocua, being dependant on the levels of antimicrobials used (Figure 1). For P. fluorescens and L. innocua, the effect became additive when PS concentration approached to $1000 \mathrm{ppm}$ (Figure 1, panels B and C). Buncic et al. (1995) reported that the antilisterial action of lactate $(4.0 \%)$ and sorbate $(0.3 \%)$ was similar to the effect of PS or SL alone. In the case of $S$. putrefaciens, a possible synergistic effect of PS and SL was observed since 18000 ppm of SL alone did not inhibit its growth (Table 1), but inclusion SL concentrations lower than 18000 ppm allowed decreasing the amount of PS. As an example, the addition of 9000 of SL decreased PS content from 4500 to 1 $800 \mathrm{ppm}$ being the estimated FIC lower than 0.9. Finally, no interaction between both antimicrobials was verified on the inhibitory action on L. plantarum.

A

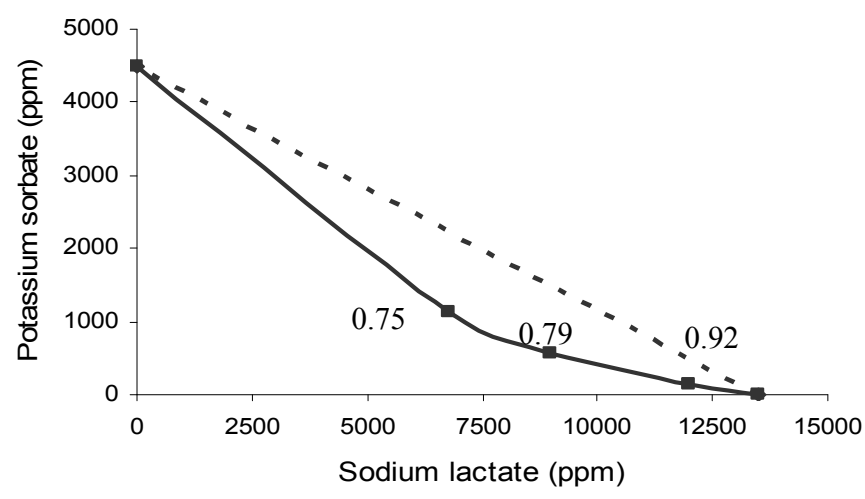

B
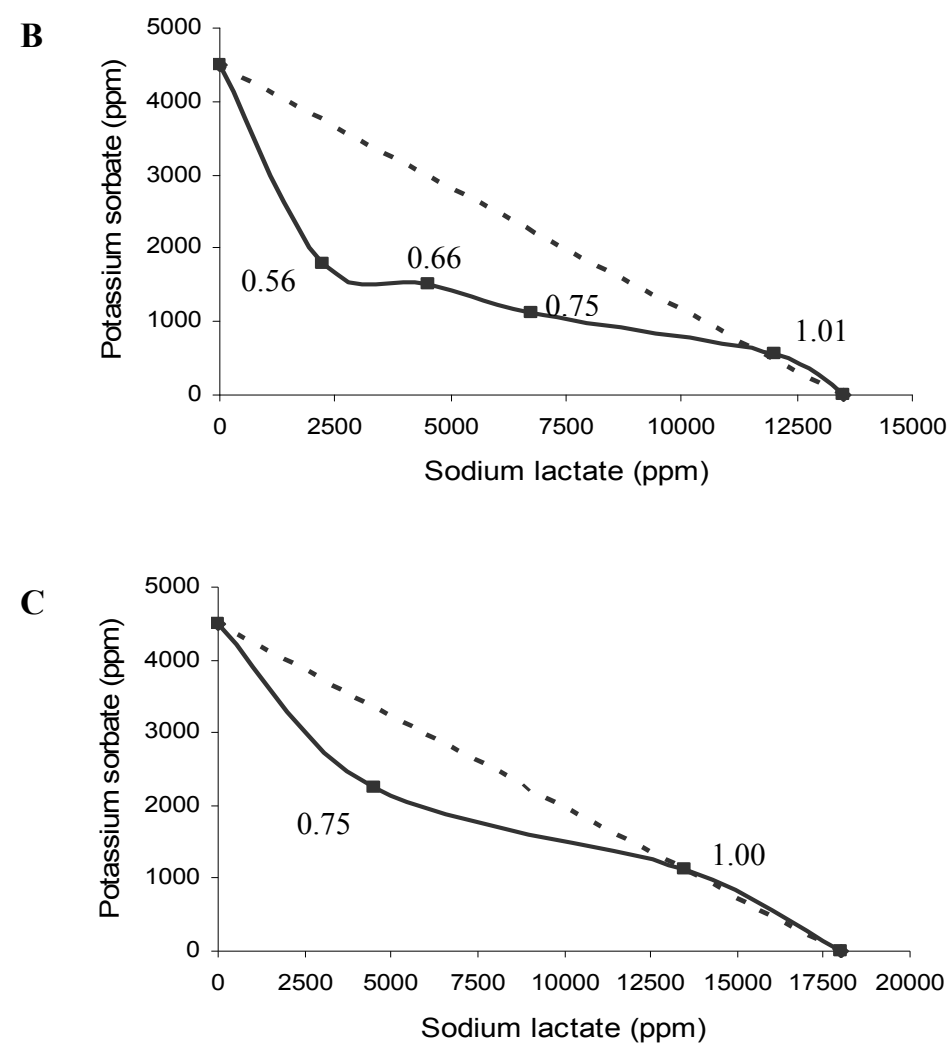

Figure 1. Isobolograms of potassium sorbate and sodium lactate minimum inhibitory concentrations against $P$. aeruginosa (panel A), P. fluorescens (panel B) and L. innocua (panel C). Numbers represented near experimental points are FIC indexes 


\subsection{Antimicrobial Mixtures on Fish Homogenates}

According to the results obtained in the previous section, mixtures of chitosan with SL, nisin or PS and mixture of SL and PS exerted a synergistic effect on the inhibition of, at least, one of the microorganisms studied. However, combinations containing PS were discarded since the levels of this antimicrobial needed to produce inhibition of growth may have adverse effects on the sensory characteristics of foods. In general, concentrations of sorbic acid, used as food preservative, are lower than $3000 \mathrm{ppm}$, since higher levels may cause undesirable changes in the taste of foods (Sofos, 2000).

The combination of chitosan and SL was tested at two levels. Figure 2 shows the effect of antimicrobials against the target microorganism growth. Between them, spoilage bacteria and L. innocua showed different trends.

At baseline there were no differences between control homogenates (C), homogenates with $40 \mathrm{ppm}$ of chitosan and $13500 \mathrm{ppm}$ of SL $\left(\mathrm{Ch}_{1}-\mathrm{SL}_{1}\right)$, and homogenates with $400 \mathrm{ppm}$ of chitosan and $27000 \mathrm{ppm}$ of SL $\left(\mathrm{Ch}_{2}-\mathrm{SL}_{2}\right)$ on the growth of deteriorative microorganisms, except for P. fluorescens (Figure 2 panels A, B, and C). In this case, a slight decrease in bacterial populations in $\mathrm{Ch}_{1}-\mathrm{SL}_{1}$ and $\mathrm{Ch}_{2}-\mathrm{SL}_{2}$, compared to $\mathrm{C}$, was observed (Figure 2, panel B).

After 24 and 72 hours of incubation at $30^{\circ} \mathrm{C}$, differences were found between the systems. Mixtures of chitosan and SL succeeded in reducing the growth of microorganisms over time and the magnitude of the effect depended on the antimicrobial concentration added. As an example, the inoculated level of P. aeruginosa in $\mathrm{Ch}_{1}-\mathrm{SL}_{1}$ was reduced $3.6 \log$ cycles after 24 hours with respect to $\mathrm{C}$ whereas a reduction of $7.4 \log$ cycles was observed in $\mathrm{Ch}_{2}-\mathrm{SL}_{2}$. After 72 hours, the populations of $\mathrm{C}$ and $\mathrm{Ch}_{1}-\mathrm{SL}_{1}$ reached $10.2 \log$ cycles, while in $\mathrm{Ch}_{2}-\mathrm{SL}_{2}$ no growth was detected (Figure 2, panel A). Regarding to S. putrefaciens, C population increased gradually, while it was not detectable in $\mathrm{Ch}_{1}-\mathrm{SL}_{1}$ and $\mathrm{Ch}_{2}-\mathrm{SL}_{2}$ (data not shown).

A

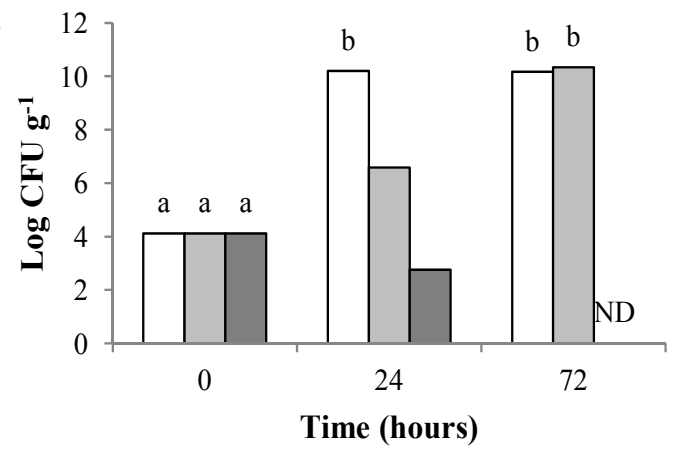

C

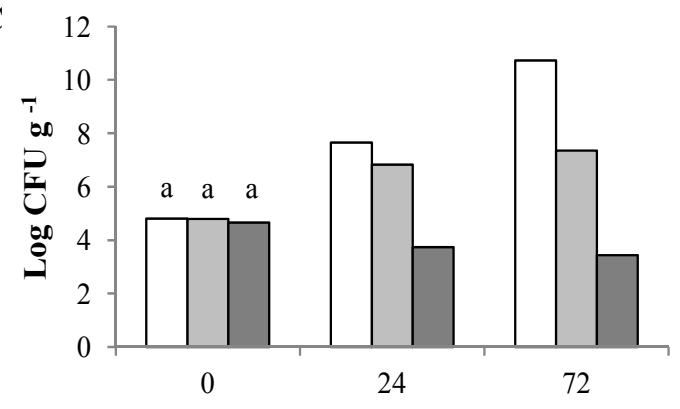

Time (hours)
B
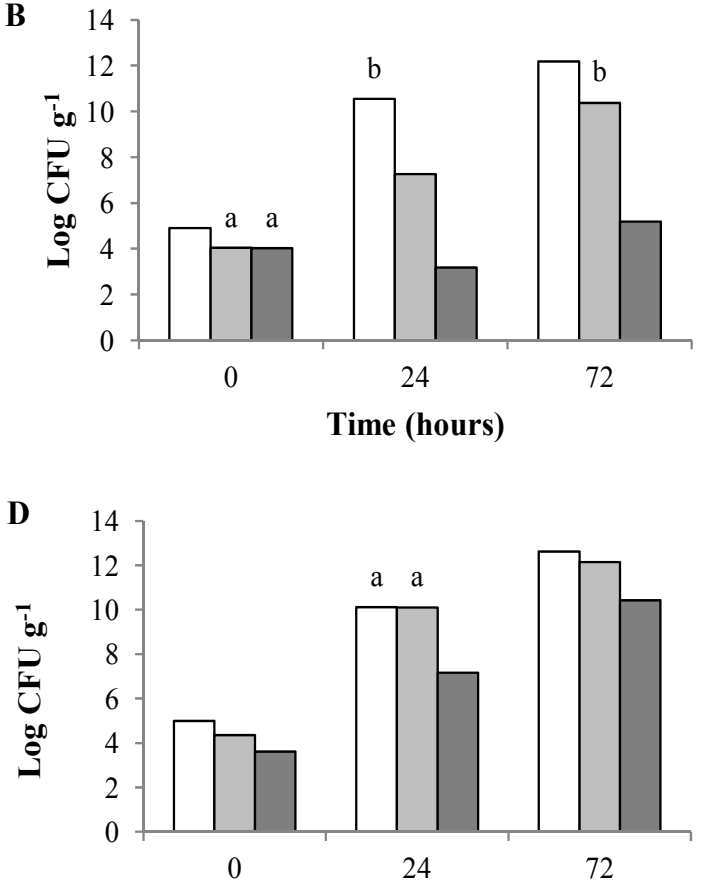

Time (hours)

Figure 2. Effect of mixtures of chitosan and SL on bacterial populations in fish homogenates stored at $30^{\circ}$ C. $P$. aeruginosa (panel A), P. fluorescens (panel B), L. plantarum (panel C), and L. innocua (panel D), $\square$ control without antimicrobials (C), $\square 40 \mathrm{ppm}$ of chitosan and $13500 \mathrm{ppm}$ of SL $\left(\mathrm{Ch}_{1}-\mathrm{SL}_{1}\right), \square 400 \mathrm{ppm}$ of chitosan and $27000 \mathrm{ppm}$ of SL $\left(\mathrm{Ch}_{2}-\mathrm{SL}_{2}\right)$. Columns with the same letter are not significantly different $(\alpha: 0.05 \%)$. Columns without letters are significantly different $(\alpha: 0.05 \%)$. ND: Growth no detected

Concerning L. innocua addition of mixtures of chitosan and SL exerted a slight inhibitory action, especially for $\mathrm{Ch}_{2}-\mathrm{SL}_{2}$ (Figure 2, panel D). 
The mixture of chitosan and nisin was tested only against S. putrefaciens and L. innocua since no interaction between antimicrobials were observed for the other microorganisms in laboratory broth. No effect of antimicrobials was detected at the beginning of the test (Figure 3). This trend was also observed for L. innocua in homogenates $\mathrm{Ch}_{3}-\mathrm{N}_{1}$ and $\mathrm{Ch}_{4}-\mathrm{N}_{2}$ after 24 hours of storage (Figure 3, panel A). However, the presence of 300 ppm of chitosan and $3000 \mathrm{IU} \mathrm{g}^{-1}$ of nisin $\left(\mathrm{Ch}_{4}-\mathrm{N}_{2}\right)$ produced a reduction of $2.3 \mathrm{log}$ cycles with respect to control homogenates (C) after 72 hours of incubation at $30^{\circ} \mathrm{C}$. Regarding to S. putrefaciens (Figure 3, panel B), in homogenates $\mathrm{Ch}_{3}-\mathrm{N}_{1}$ and $\mathrm{Ch}_{4}-\mathrm{N}_{2}$ bacteria populations decreased during the storage compared to the control homogenates $(\mathrm{C})$.

A

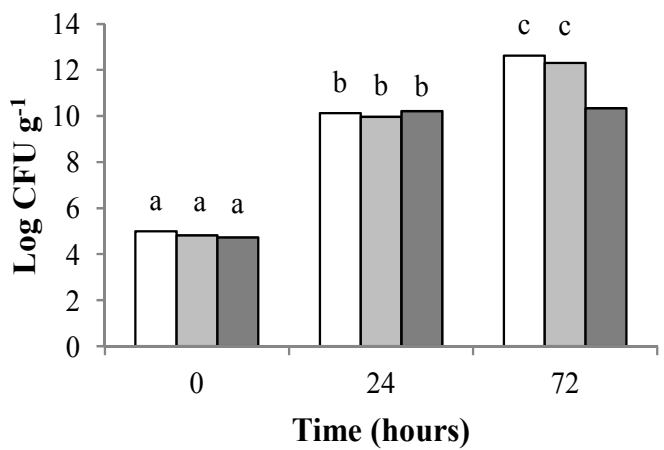

B

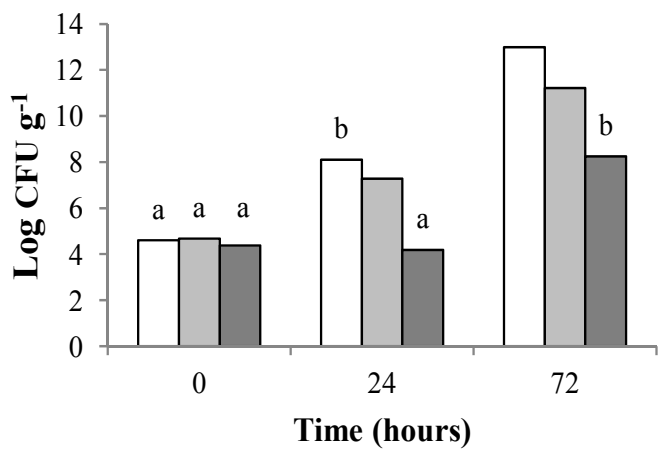

Figure 3. Effect of mixtures of chitosan and nisin on bacterial populations in fish homogenates stored at $30^{\circ} \mathrm{C}$. $L$. innocua (panel A) and S. putrefaciens (panel B). $\square$ control without antimicrobials (C), $\square 60$ ppm of chitosan and $600 \mathrm{IU} \mathrm{g}^{-1}$ of nisin $\left(\mathrm{Ch}_{3}-\mathrm{N}_{1}\right), \square 300 \mathrm{ppm}$ of chitosan and $3000 \mathrm{IU} \mathrm{g}^{-1}$ of nisin $\left(\mathrm{Ch}_{4}-\mathrm{N}_{2}\right)$. Columns with the same letter are not significantly different $(\alpha: 0.05 \%)$. Columns without letters are significantly different $(\alpha$ :

$$
0.05 \%)
$$

\section{Conclusion}

In laboratory media, most preservatives inhibited the growth of studied bacteria. Isobolograms and FIC index showed that the combined used of chitosan-PS, or chitosan-SL or PS-SL in laboratory broth interacted synergistically against the growth of $L$. innocua and both Pseudomonas. Regarding S. putrefaciens, the combination of chitosan with PS, or nisin exerted a synergistic action. The same trend was verified for the mixture of SL with chitosan or PS. Only the combination of SL and chitosan acted synergistically against $L$. plantarum. In summary, chitosan-SL mixture was the most effective controlling the growth of all studied bacteria. Chitosan-PS mixture was also effective, but the concentration of PS needed may produce a negative impact on the sensory characteristics of fish.

In fish homogenates, chitosan in combination with SL or nisin, achieved the reduction of bacterial population. It must be highlighted that the mixture of chitosan and SL was the most effective one, being useful for the preservation of minimally processed fish together with other stress factors.

\section{Acknowledgements}

The support of Universidad de Buenos Aires and Consejo Nacional de Investigaciones Científicas y Técnicas de la República Argentina is gratefully acknowledged.

\section{References}

Abou-Zeid, K. A., Yoon, K. S., Oscar, T. P., Schwarz, J. G., Hashem, F. M., \& Whiting, R. C. (2007). Survival and growth of Listeria monocytogenes in broth as a function of temperature, $\mathrm{pH}$, and potassium lactate and sodium diacetate concentrations. Journal of Food Protection, 70, 2620-2625.

Adams, M. (2003). Nisin in multifactorial food preservation. In: Natural antimicrobials for the minimal processing of foods (edited by S. Roller). Cambridge, England: Woodhead Publishing Limited and CRC Press LLC. http://dx.doi.org/10.1533/9781855737037.11

Aran, N. (2001). The effect of calcium and sodium lactates on growth from spores of Bacillus cereus and Clostridium perfringens in a 'sous-vide' beef goulash under temperature abuse. International Journal of Food Microbiology, 63, 117-123. http://dx.doi.org/10.1016/S0168-1605(00)00412-8

Boskou, G., \& Debevere, J. (1998). In vitro study of TMAO reduction by Shewanella putrefaciens isolated from 
cod fillets packed in modified atmosphere. Food Additives and Contaminants, 15(2), 229-236. http://dx.doi.org/10.1080/02652039809374634

Buncic, S., Fitzgerald, C. M., Bell, R. G., \& Hudson, J. A. (1995). Individual and combined listericidal effects of sodium lactate, potassium sorbate, nisin and curing salts at refrigeration temperature. Journal of Food Safety, 15, 247-264. http://dx.doi.org/10.1111/j.1745-4565.1995.tb00137.x

Cai, J., Yang, J., Wang, C., Hu, Y., Lin, J., \& Fan, L. (2010). Structural characterization and antimicrobial activity of chitosan (CS-40)/nisin complexes. Journal of Applied Polymer Science, 116, 3702-3707. http://dx.doi.org/10.1002/app.31936

Devlieghere, F., Vermeulen, A., \& Debevere, J. (2004). Chitosan: Antimicrobial activity, interactions with food components and applicability as a coating on fruit and vegetables. Food Microbiology, 21, 703-714. http://dx.doi.org/10.1016/j.fm.2004.02.008

Dykes, G. A., Hancock, R. E. W., \& Hastings, J. W. (1998). Structural variations in nisin associated with different membrane mimicking and $\mathrm{pH}$ environments. Biochemical and Biophysical Research Communications, 247, 723-727. http://dx.doi.org/10.1006/bbrc.1998.8849

Fan, W., Sun, J., Chen, Y., Qiu, J., Zhang, Y., \& Chi, Y. (2009). Effects of chitosan coating on quality and shelf life of silver carp during frozen storage. Food Chemistry, 115, 66-70. http://dx.doi.org/10.1016/j.foodchem.2008.11.060

Fang, T. J., Chen, C. Y., \& Chen, H. H. L. (1997). Inhibition of Staphylococcus aureus and Bacillus cereus on a vegetarian food treated with nisin combined with either potassium sorbate or sodium benzoate. Journal of Food Safety, 17, 69-87. http://dx.doi.org/10.1111/j.1745-4565.1997.tb00178.x

Friedly, E. C., Crandall, P. G., Ricke, S., O’Bryan, C. A., Martin, E. M., \& Boyd, L. M. (2008). Identification of Listeria innocua surrogates for Listeria monocytogenes in hamburger patties. Journal of Food Science, 73(4), 174-178. http://dx.doi.org/10.1111/j.1750-3841.2008.00719.x

Gandhi, M., \& Chikindas, M. L. (2007). Listeria: A foodborne pathogen that knows how to survive. International Journal of Food Microbiology, 113, 1-15. http://dx.doi.org/10.1016/j.ijfoodmicro.2006.07.008

Gram, L., \& Dalgaard, P. (2002). Fish spoilage bacteria-problems and solutions. Current Opinion in Biotechnology, 13, 262-266. http://dx.doi.org/10.1016/S0958-1669(02)00309-9

Hurst, A., \& Hoover, D. G. (1993). Nisin. In: Antimicrobials in Foods (edited by P. M. Davidson \& A. L. Branen). pp. 369-394. New York, USA: Marcel Dekker, Inc.

Juneja, V. K. (2006). Delayed Clostridium perfringens growth from a spore inocula by sodium lactate in sous-vide chicken products. Food Microbiology, 23, 105-111. http://dx.doi.org/10.1016/j.fm.2005.03.002

Long, C., \& Phillips, C. A. (2003). The effect of sodium citrate, sodium lactate and nisin on the survival of Arcobacter butzleri NCTC 12481 on chicken. Food Microbiology, 20, 495-502. http://dx.doi.org/10.1016/S0740-0020(02)00176-4

Lopez Malo Vigil, A., Palou E., Parish M. E., \& Davidson, P. M. (2005). Methods for activity assay and evaluation of results. In: Antimicrobials in Foods, pp. 659-680. Boca Ratón, Florida, USA: CRC Press Taylor and Francis Group.

National Committee for Clinical Laboratory Standards. (1999). Methods for determining bactericidal activity of antimicrobial agents. Approved guideline. NCCLS document M26-A, National Committee for Clinical Laboratory Standards. Wayne, PA, USA.

Neetoo, H., Ye, M., \& Chen, H. (2008). Potential antimicrobials to control Listeria monocytogenes in vacuum-packaged cold-smoked salmon paté and fillets. International Journal of Food Microbiology, 123, 220-227. http://dx.doi.org/10.1016/j.ijfoodmicro.2008.02.001

No, H. K., Meyers, S. P., Prinyawiwatkul, W., \& Xu, Z. (2007). Applications of chitosan for improvement of quality and shelf life of foods: A review. Journal of Food Science, 72(5), 87-100. http://dx.doi.org/10.1111/j.1750-3841.2007.00383.x

Nykänen, A., Weckman, K., \& Lapveteläinen, A. (2000). Synergistic inhibition of Listeria monocytogenes on cold-smoked rainbow trout by nisin and sodium lactate. International Journal of Food Microbiology, 61, 63-72. http://dx.doi.org/10.1016/S0168-1605(00)00368-8

Olafsdóttir, G., Martinsdóttir, E., Oehlenschläger, J., Dalgaard, P., Jensen, B., Undeland, I., ... Nilsen, H. (1997). 
Methods to evaluate fish freshness in research and industry. Trends in Food Science \& Technology, 8, 258-265. http://dx.doi.org/10.1016/S0924-2244(97)01049-2

Owen, R. J., \& Palombo, E. A. (2007). Anti-listerial activity of ethanolic extracts of medicinal plants, Eremoplila alternifolia and Eremophila duttonii, in food homogenates and milk. Food Control, 18, 387-390. http://dx.doi.org/10.1016/j.foodcont.2005.11.004

Roa, V., \& Tapia de Daza, M. S. (1991). Evaluation of water activity measurement with a dew point electronic humidity meter. Lebensmittel Wissenschaft und Technologie Food Science and Technology, 24, 208-213.

Roller, S. (2003). Introduction. In: Natural antimicrobials for the minimal processing of foods (edited by S. Roller). Cambridge, England: Woodhead Publishing Limited and CRC Press LLC.

Sallam, K. I. (2007). Antimicrobial and antioxidant effects of sodium acetate, sodium lactate, and sodium citrate in refrigerated sliced salmon. Food Control, 18, 566-575. http://dx.doi.org/10.1016/j.foodcont.2006.02.002

Singh, P. K., Tack, B. F., McCray, P. B. Jr., \& Welsh, M. J. (2000). Synergistic and additive killing by antimicrobial factors found in human airway surface liquid. American Journal of Physiology-Lung Cellular and Molecular Physiology, 279, 799-805.

Sofos, J. N. (2000). Sorbic acid. In: Natural food antimicrobial systems (edited by A. S. Naidú) pp. 637-656. Boca Raton, FL, USA: CRC Press, Inc. http://dx.doi.org/10.1201/9781420039368.ch23

Stekelenburg, F. K., \& Kant-Muermans, M. L. T. (2001). Effects of sodium lactate and other additives in a cooked ham product on sensory quality and development of a strain of Lactobacillus curvatus and Listeria monocytogenes. International Journal of Food Microbiology, 66, 197-203. http://dx.doi.org/10.1016/S0168-1605(00)00521-3

Thomas, L. V., \& Delves Broughton Hoover, D. G. (2005). Nisin. In: Antimicrobials in Foods (edited by Davidson, P. M., Sofos, J. N. \& Branen, A. L). pp. 659-680. Boca Ratón, Florida, USA: CRC Press Taylor and Francis Group.

Thomas, L. V., Clarkson, M. R., \& Delves-Broughton, J. (2000) Nisin. In: Natural food antimicrobial systems (edited by A. S. Naidú) Pp. 463-524. Boca Raton, FL, USA: CRC Press, Inc.

Tin, S., Sakharkar, K. R., Lim, C. S., \& Sakharkar, M. K. (2009). Activity of chitosans in combination with antibiotics in Pseudomonas aeruginosa. International Journal of Biological Sciences, 5, 153-160. http://dx.doi.org/10.7150/ijbs.5.153

Vasconez, M. B., Flores, S. K., Campos, C. A., Alvarado, J., \& Gerschenson, L. N. (2009). Antimicrobial activity and physical properties of chitosan-tapioca starch based edible films and coatings. Food Research International, 42, 762-769. http://dx.doi.org/10.1016/j.foodres.2009.02.026

Ye, M., Neetoo, H., \& Chen, H. (2008a). Effectiveness of chitosan-coated plastic films incorporating antimicrobials in inhibition of Listeria monocytogenes on cold-smoked salmon. International Journal of Food Microbiology, 127, 235-240. http://dx.doi.org/10.1016/j.ijfoodmicro.2008.07.012

Ye, M., Neetoo, H., \& Chen, H. (2008b). Control of LIsteria monocytogenes on ham steaks by antimicrobials incorporated into chitosan-coated plastic films. Food Microbiology, 25, 260-268. http://dx.doi.org/10.1016/j.fm.2007.10.014

Yeh, J. Y., Hoogetoorn, E., \& Chen, J. (2004). Influence of calcium lactate on the fate of spoilage and pathogenic microorganisms in orange juice. Journal of Food Protection, 67(7), 1429-32. 